\title{
Reflections on the GAO Triad Report on the Nuclear Triad
}

Science and Global Security 6, 383-393 (1997)

(this is the submitted version, essentially the same as published)

(GAO Tabular conclusions are in the next file)

\author{
David Hafemeister \\ Physics Department \\ California Polytechnic State University \\ San Luis Obispo, CA 93407
}

\begin{abstract}
Senate Hearings on the GAO report on the nuclear triad and on the START treaty showed that vulnerabilities of the U.S. triad were vastly over-stated, that the performance of new projected strategic systems was over-estimated, and that the performance of existing U.S. strategic systems was underestimated. These exaggerations enhanced the psychological (Freud) aspects of the Cold War and compromised logic (Newton).

With the end of the Cold War it is imperative that we re-examine the basic premises that guided the choices of the strategic nuclear systems. The initial bottom line is that these systems were successful in that they did deter nuclear war without destroying either or both superpowers. However, now that the emotion of the conflict has passed, the effectiveness of the nuclear triad should be examined to determine how much was enough and which technical conventional wisdoms were incorrect.

As this paper documents, incorrect technical estimates took place. These errors (and/or exaggerations) caused the U.S. to greatly increase the capabilities of its nuclear triad. At a minimum, these errors were fiscally wasteful, and at a maximum they could have endangered the stability between the countries. This paper examines technical aspects of the robustness of the triad, rather than the psychological causes and consequences of worst-case analysis. When more historical data becomes available, other authors should examine the effects of the U.S. nuclear build up on Soviet behavior (e.g., why Gorbachev was willing to let the Berlin wall fall and reduce the Warsaw Pact forces by $60 \%$ without requiring NATO reductions). The technical conclusions of this paper are based on the author's staffing 20 hearings [1] on the START treaty before the Senate Foreign Relations Committee, and the Senate Governmental Affairs Committee hearing [2] on the General Accounting Office report, The U.S. Nuclear Triad: GAO's Evaluation of the Strategic Modernization Program. The GAO study produced a massive eight volume classified report which, according to the GAO, was the most complete examination of strategic nuclear forces in the past three decades.
\end{abstract}

\section{The Triad as a Whole}

The strategic triad, with its three legs of land-, sea- and air-based nuclear weapons, was both the capstone of the possible conflict and the deterrent that separated the two dance-partners. Were the 
conventional wisdoms correct? Was each leg of the triad so vulnerable that the other two legs were necessary to truly deter? Was the Cold War driven by "worst-case" analysis? The GAO concluded that, indeed, the U.S. had used worst-case analysis by:

(1) overstating the Soviet threat to the U.S. triad,

(2) underestimating the performance of existing U.S. systems, and

(3) overestimating the performance of new U.S. systems.

In response to the hearing on the GAO report, former Secretary of defense Casper Weinberger agreed [3] that worst-case analysis had been used:

"Yes, we used a worst-case analysis. You should always use a worst-case analysis in this business. You can't afford to be wrong. In the end, we won the Cold War, and if we won by too much, if it was overkill, so be it."

Thus, there is no disagreement between GAO and Weinberger that worst-case analysis was used in winning the Cold War. Because of uncertainties in intelligence information and because leaders are motivated to justify and rationalize their military investments, it is expected that worst-case analysis will be used. If this is true, how will the Congress know what to believe when appropriating billions and trillions of dollars? Given that governments can not fiscally survive if their trusted advisors always used worst-case analysis, it is necessary to restrain the psychological and economic motives for exaggeration.

\section{Silo Vulnerability}

There is no disagreement that 33,000 U.S. warheads and 45,000 Soviet warheads was colossal over-kill when one considers the gross vulnerability of cities. There has always been disagreement on the need for counterforce ability to attack the other side's silo-based missiles. In 1981, Richard Perle, then Assistant Secretary of defense, gave his opinion [4] on the vulnerability of U.S. missile silos and the inability of the U.S. to destroy Soviet silos:

"Yet as we examine the SALT II treaty produced during the 1970s, the constraints it entailed would have permitted the Soviet Union to continue expanding and refining its offensive forces so that sometime during the life of the treaty it would have had the capacity to strike a knock-out blow against the landbased missile leg of the U.S. strategic triad. And it seem equally certain that the U.S. missile force would have been unable to threaten the Soviet ICBM force."

The GAO's findings in Table 1 refute Perle's charge that the Soviets "would have had the capacity to strike a knock-out blow against the land-based missile leg" and that the D-5/MX "U.S. missile force would have been unable to threaten the Soviet ICBM force." In her testimony before the Governmental Affairs Committee, Assistant Comptroller General Eleanor Chelimsky stated [2] that the silos were not nearly as vulnerable as the government had claimed:

"In the case of the land leg, we found that the claimed 'window of vulnerability' caused by improved Soviet missile capability against our silo-based ICBMs was overstated on three counts. First, it did not recognize the existence of sea and air leg deterrence -- that is, the likelihood that the Soviets would hesitate to launch an all-out attack on the ICBM silos, given their inability to target submerged U.S. 
SSBNs or on-alert bombers and their thousands of warheads that could be expected to retaliate. Second, the logic behind the claim assumed only the highest estimates for such key Soviet missile performance dimensions as accuracy, yield and reliability, while at the same time discounting very substantial uncertainties about performance that could not have been resolved short of nuclear conflict. Third, it ignored the ability of U.S. early warning systems to detect a Soviet ICBM attack, and thereby, allow a reasonably rapid response."

During the hearings on the START treaty, the highest U.S. military figure, General Colin Powell, Chairman of the Joint Chiefs of Staff, seemed to concur with this conclusion [1] when he responded to a hypothesized question on possible massive Soviet cheating: "... but even if they had 20,000 SS-25s, I am not sure what that truly does for them. As long as I have survivable systems at sea, for example, what would they do with these? What incentive is there for them to move in that direction?"

Powell's conclusion was consistent with the National Academy of Science's conclusion [5]: "In the agreements that follow the START treaty, the United States and the Soviet Union should reduce the number of nuclear warheads in their strategic forces to 3,000 to 4,000 actual warheads, a reduction of as much as a factor of three below anticipated START levels." During the course of the arms race a number of authors have estimated the robustness of the surviving nuclear force by using sensitivity analysis [6] with nuclear exchange models ("red attacks blue"). These calculations have shown that break-outs from arms control treaties by the other Party did not greatly affect the result. An attack can be enhanced by increasing the numbers and yields of warheads, by making the warheads more accurate and reliable, and by discovering that one's silos were not as hard as estimated. By varying the various parameters, one can show that the U.S. has always had a robust triad and the marginal utility of additional warheads beyond START levels is very small.

\section{Submarine Vulnerability}

In a similar fashion, GAO concluded that the threats to the submarines had also been exaggerated. GAO concluded that the threat had been overstated in "unsubstantiated allegations about likely future breakthroughs in Soviet submarine detection technologies, along with the underestimation of the performance and capabilities of our own nuclear powered ballistic missile submarines." These exaggerated threats to the SSBNs were then used as a justification for costly modernization in the other legs of the triad to cover the possible vulnerabilities to the SSBNs. The threats to the SSBNs have been categorized [7] as "non-acoustic anti-submarine warfare," which uses radar, laser, or infrared detectors on satellites to search out the signatures of the SSBNs. Two submarine signatures that have been discussed are (1) the slightly raised ocean surface above a moving submarine (the Bernoulli hump) and (2) the V-shaped wave above the moving submarine (the Kelvin wave). In principle, these signatures might be observed from submarines near the surface if one knows where to look with syntheticaperture radar accompanied with significant computer capabilities. The U.S. and Russia have carried out joint experiments on these phenomena, but the GAO concluded that these experiments do not give evidence for concern for survivability of the SSBNs when they are at sea. In fact, it is very difficult to observe the very small oceanographic signals from submerged submarines. When SSBNs observe radar from satellites, they can easily diminish their reflective signature by cruising just a little deeper. Even if the submarines were silly enough to cruise too close to the surface, the job of coordinating a very large number of satellites to observe some 14-18 SSBN submarines, as well as doing the on-board computer analysis to obtain near-real time data for targeting would be too large and too expensive. General 
Powell concurred by stating: "based on our first examination of the claims [of a successful non-acoustic anti-submarine warfare technology], we do not believe that they are accurate .... [but] we will explore this to make sure that we are correct, that it is not feasible." Nonetheless, in their report on the START treaty, the Senate Armed Service Committee recommended [1] that a condition be added to the START II Treaty that would give "strong support for the joint U.S./Russian submarine detection program."

GAO had access to the classified data on submarine delectability and discussed these issues with the intelligence and military communities. GAO concluded [2] that "Our specific finding, based on operational test results, was that submerged SSBNs are even less detectable than is generally understood, and that there appear to be no current or long-term technologies that would change this. Moreover, even if such technologies did exist, test and operational data show that the survivability of the SSBN fleet would not be in question." (emphasis by GAO)

\section{Vulnerability of Penetrating Bombers}

In a similar vein, the threat to heavy bombers was also exaggerated. In her analysis [8] of the CIA Team B report of 1976, Anne Cahn pointed out that the extreme worst-case analysis by Richard Pipe's Team B was a leading factor in the political pressure for the U.S. build-up under President Carter (MX and B-2) and President Reagan. The Team B report [9] on Soviet Low Altitude Air Defense: An Alternative View concludes that "it is not inconsistent with current evidence that the Soviets believe they have and may already posses the inherent ability to prevent most, if not all, penetrating bombers (of the kind presently in the force, in raid sizes of a few hundred) from reaching targets the Soviets value." This conclusion is obviously wrong because it states "most, if not all" implies a kill probability of better than $99 \%$ which is far beyond expectation. In addition, cruise missiles have been added to the B-52s which allow them to attack the Soviet Union while over the ocean. This overly strong assessment on Soviet air defense was based on projections of significant improvements in the kill probabilities and reliabilities of improved Soviet SA-2s and SA-3s, as well as their very extensive deployments. Although these projected enhancements never came close to being realized, they propelled the U.S. into the B-1 and B-2 bomber programs, both of which never materialized as projected and were budget breakers to boot. GAO concluded [2] that "the Soviet air defense threat that the B-2 had been created to address was never in fact deployed."

\section{ICBMs vs. SLBMs}

U.S. fears of "Minuteman and Peacekeeper (MX) vulnerability" were always driven by concerns that the U.S. would not have a prompt, reliable, well-coordinated response to aim at Soviet hard targets. The GAO [2] disagreed with this concern by stating that silo vulnerability was exaggerated (see "silo vulnerability" above) and by concluding that the offensive power of the sea leg was essentially equivalent to that of the land leg: "the sea leg's performance has been understated (or poorly understood) on a number of critical dimensions. Test and operational patrol data show that the speed and reliability of day-to-day communications to submerged, deployed SSBNs are far better than widely believed, and about the equal in speed and reliability of communications to ICBM silos. Yet conventional wisdom gives much higher marks to ICBM command and control responsiveness than to that of submarines. In point of fact, SSBNs are in essentially constant communication with national command authorities and, depending on the scenario, SLBMs from submarine platforms would be 
almost as prompt as ICBMs in hitting enemy targets. Other test data show that the accuracy and reliability of the Navy's D-5 SLBM are about equal to DOD's best estimates for the Peacekeeper. Further, its warhead has a higher yield than the Peacekeeper's. In short we estimate that the D-5 has a hard target kill capability about equal to the Peacekeeper's, while its platforms remain virtually undetectable, unlike easily located silos."

\section{Conclusion}

We have summarized some of the technical findings on the U.S. strategic triad and in examining these technical facts it is clear that the U.S. exaggerated the threats to its own triad. These exaggerated facts and projections were the main driving force for the large scale modernization of the U.S. triad. In hindsight we see that the projected threat to U.S. strategic submarines was not credible, the vulnerability of U.S. penetrating bombers was overstated, and the vulnerability of our silos was exaggerated by using worst-case parameters. In the future if the U.S. ever faces new strategic build-ups by evil empires, the technical history of the strategic triad should be re-examined to avoid these errors. In answer to the lead question of this paper, exaggerations of U.S. vulnerability to Soviet threats probably resulted more from the need to rationalize arms race policies than from rational analysis of military facts. The ultimate total cost of U.S. nuclear weapons systems was about \$4 trillion [11]. The size and scope of the U.S. strategic nuclear triad was largely determined by these worst-case exaggerations and by psychological theories [10] about effects of arms race policies on U.S. morale and Soviet perceptions. It is my strong conclusion that Freud defeated Newton.

David Hafemeister is Professor of Physics at the California Polytechnic State University. He was formerly Professional Staff Member at the Senate Foreign Relations Committee (1990-92) and the Senate Governmental Affairs Committee (1992-93), the Office of Senator John Glenn (1975-77) and the State Department $(1977-79,1987)$, working on arms control matters.

\section{References}

1. U.S. Senate Foreign Relations Committee, The START Treaty, S.Hrg. 102-607 (Parts 1-2), S.Exec. Report 102-53, 1992.

2. U.S. Governmental Affairs Committee, Evaluation of the U.S. Strategic Triad, S.Hrg 103-457, 1994. U.S. General Accounting Office, The U.S. Nuclear Triad: GAO's Evaluation of the Strategic Modernization Program (plus 8 classified volumes), GAO/T-PEMD-93-5, 1993.

3. C. Weinberger, New York Times, June 28, 1993.

4. R. Perle, introduction to Beyond the SALT II Failure, J. Lehman and S. Weiss, Praeger, New York, 1981.

5. National Academy of Sciences, The Future of the U.S.-Soviet Nuclear Relationship, National Academy Press, 1991. 
6. D. Hafemeister, "Breakout from Arms Control Treaties: A Sensitively Analysis of the Threat to National Security," in Arms Control Verification, ed. by K. Tsipis, D. Hafemeister and P. Janeway, Pergamon-Brassey's, Washington, DC, 1985. M. May, G. Bing and J. Steinbrunner, "Arsenals after START: The Implications of Deep Cuts," International Security 13, no. 1, 90-133 (1988).

7. T. Stefanick, "The Nonacoustic Detection of Submarines," Scientific American 258, no. 3, $41-47$ (1988) and 268, no. 2, 32 (1993).

8. A Cahn, "Team B: The Trillion Dollar Experiment," Bull. At. Scientists 49, no. 3, 22-27 (1993).

9. C. Lerch and CIA Team B, "Soviet Low Altitude Air Defense: An Alternative View," In Intelligence Community Experiment in Competitive Analysis, December 1976 (partially declassified Sept. 16, 1992).

10. S. Kull, Minds at War: Nuclear Reality and the Inner Conflicts of Defense Policy Makers, Basic Books, NY, 1988. L. Nelson and G. Beardsley, "Towards an Interdisciplinary Model of Barriers to Nuclear Arms Control," Social Science Journal 24, 375-388 (1987).

11. S. Schwartz, et al, "Four Trillion Dollars and Counting," Bull. At. Sci. 51, $32-52$ (Nov. 1995). The U.S. Nuclear Weapons Cost Study Project, Atomic Audit: The Costs and Consequences of U.S. Nuclear Weapons, 1940-1995, Brookings, Washington, D.C., to be published, 1997. 